Check for updates

Cite this: RSC Adv., 2019, 9, 10465

Received 21st December 2018 Accepted 7th March 2019

DOI: $10.1039 / c 8 r a 10459 j$

rsc.li/rsc-advances

\section{Alleviating concentration polarization: a micro three-electrode interdigitated glucose sensor based on nanoporous gold from a mild process $\uparrow$}

\author{
Guokang Fan, ${ }^{\text {ab }}$ Peng Sun, ${ }^{\star a b}$ Jie Zhao, ${ }^{\star c}$ Dongxue Han, ${ }^{\text {de }}$ Li Niu ${ }^{\text {de }}$ \\ and Guofeng Cui iD *ab
}

Precisely detecting the concentration of glucose in the human body is an attractive way to prevent or diagnose diabetes. Compared with the traditional enzyme-based electrochemical glucose sensors, the non-enzymatic ones have gradually come to people's attention recently. By integrating three electrodes into one device, glucose sensors can achieve superior performance and are convenient to carry. Herein, a non-enzymatic three-electrode interdigitated glucose sensor (TEIDGS) based on nanoporous gold is designed and fabricated. To our best knowledge, it is the first time that interdigitated electrodes are combined in a single non-enzymatic glucose sensor device. Due to the advantage of the interdigitated structure and the smart design of the three-electrode circuit board, the TEIDGS can effectively reduce concentration polarization and achieve a high detective sensitivity for glucose of $1217 \mu \mathrm{A} \mathrm{mM} \mathrm{mm}^{-1} \mathrm{~cm}^{-2}$ and $343 \mu \mathrm{A} \mathrm{mM}^{-1} \mathrm{~cm}^{-2}$ in the ranges of $0.001-0.590 \mathrm{mM}$ and $0.59-7.00 \mathrm{mM}$, respectively. Moreover, a low detection limit of $390 \mathrm{nM}$ can be reached. In addition, this TEIDGS possesses excellent selectivity for glucose among other interferents. Strikingly, after three weeks of operation, it can still retain a high detection performance. This work will certainly provide an efficient structure and proper catalytic material choice for future non-enzymatic glucose sensors.

\section{Introduction}

In a healthy human body, carbohydrates are converted into glucose, and glucose is absorbed into cells with the help of insulin, thus providing enough energy for daily activities. However, people who can't produce insulin or are unable to use insulin to carry glucose into their cells may suffer from diabetes. Nowadays, diabetes has become one of the most common diseases all around the world. According to the International Diabetes Federation, approximately 425 million adults (20-79 years) are living with diabetes and by 2045 this will rise to 629 million. ${ }^{1}$ In this view, accurate monitoring and controlling of

${ }^{a}$ Key Laboratory for Polymeric Composite \& Functional Materials of Ministry of Education, School of Chemistry, Sun Yat-sen University, Guangzhou, 510275, China. E-mail:cuigf@mail.sysu.edu.cn; sunp25@mail2.sysu.edu.cn

${ }^{b}$ Key Laboratory of Low-carbon Chemistry \& Energy Conservation of Guangdong Province, Sun Yat-sen University, Guangzhou, 510275, China

${ }^{c}$ School of Mechanical and Automotive Engineering, South China University of Technology, Guangzhou, 510640, China.E-mail: zhaoj77@scut.edu.cn

${ }^{d}$ Center for Advanced Analytical Science, c/o School of Chemistry and Chemical Engineering, Guangzhou University, Guangzhou 510006, PR China

eState Key Laboratory of Electroanalytical Chemistry, c/o Engineering Laboratory for Modern Analytical Techniques, Changchun Institute of Applied Chemistry, Chinese Academy of Science, Changchun, 130022, Jilin, PR China

$\dagger$ Electronic supplementary information (ESI) available: Fig. S1-S6 and Table S1. See DOI: $10.1039 / \mathrm{c} 8 \mathrm{ra10459j}$ the blood glucose concentration in real time is crucial for the fast diagnosis and timely treatment of diabetes. Therefore, glucose sensors with high sensitivity and stability, fast response and good selectivity are in demand. ${ }^{2}$

Electrochemical glucose sensors possess several properties including rapid response, high sensitivity, good selectivity and simplicity to use compared with other glucose sensors based on other techniques. ${ }^{3-5}$ Although the enzyme-based electrochemical glucose sensors occupy a major place in the whole commercial industry, they have numerous limitations, in which the most severe one is that they are sensitive to the external environment due to the utilization of an enzyme. Thus, it has attracted many researchers' attention to develop highperformance non-enzymatic glucose sensors which can oxidize glucose directly on the electrode surface via applying a small voltage, avoiding the use of enzymes. It can overcome the problem of enzyme inactivation and shows the advantages of good stability, low cost, simplicity and reproducibility. ${ }^{\mathbf{4} 6-\mathbf{9}}$ Different kinds of materials have been applied to construct nonenzymatic glucose sensors including metals, alloys, metal oxides, and carbon. ${ }^{\mathbf{1 0 - 1 5}}$ Among all kinds of materials, nanostructure metals are one of the most potential ones since they can supply more surface active sites and exhibit much higher catalytic performance. ${ }^{\mathbf{1 6 - 2 0}}$ Nanostructure gold has received much attention due to its high catalytic activity and biocompatibility. Many reports have confirmed the availability of non- 
enzymatic glucose sensors based on gold nanomaterials. ${ }^{21-23}$ Nanoporous gold (NPG) is a novel porous material composed of pores with the size of 5-700 nm, which can be prepared by etching the complete $\mathrm{Au}$ film or the Au-based alloy. The latter method seems better since it can greatly lower the cost. ${ }^{24-27}$ Recently we have synthesized NPG through a mild process and applied it in hydrogen peroxide electroreduction and supercapacitors. ${ }^{28-31}$

The device structure is another important factor for highperformance glucose sensors. ${ }^{32,33}$ Interdigitated electrodes with small intervals possess many advantages including low ohmic drop, quick establishment of the steady-state condition, enhancement of signal-to-noise ratio and fast detection speed..$^{34-38}$ In addition, interdigitated electrodes can be easily integrated on microchips and used in all kinds of sensors, nano-generators and micro-supercapacitors. ${ }^{34,36,39-41}$ Designing the layout of each electrode on the circuit board can surely enhance the performance of the whole device. ${ }^{42,43}$ Combining the interdigitated structure with the above high-performance materials can obviously elevate the final performance of the glucose sensors.

Herein, a three-electrode interdigitated electro-chemical glucose sensor (TEIDGS) was firstly constructed by preparing NPG as the sensing electrode, Pt particles as the courter electrode and $\mathrm{Ag} / \mathrm{AgCl}$ as the reference electrode. The NPG sensing electrode was fabricated via a mild method composed of two steps: electrodepositing $\mathrm{Au}-\mathrm{Sn}$ alloy and then dealloying the Sn. The three electrodes were decorated on a precise ceramic circuit board. Due to the effective alleviation of the concentration polarization between the working and counter electrodes and the reasonable design of the reference electrode on the same circuit board, this novel TEIDGS exhibits a high glucose sensing performance, with a rather high sensitivity of $1.217 \mathrm{~mA} \mathrm{mM}^{-1}$ $\mathrm{cm}^{-2}$, a low limit detection of $390 \mathrm{nM}$ and excellent linear ranges of 1-590 $\mu \mathrm{M}$ and $0.59-7.00 \mathrm{mM}$. The excellent electrochemical performance and simple fabrication technology of the TEIDGS provides an exciting method to develop non-destructive and non-enzymatic biosensors.

\section{Experimental}

\subsection{Reagent and chemical}

The Au-Sn alloy plating solution was obtained from Huizhou Leadao Electronic Material Co., Ltd (Huizhou, China, website: http://www.leadao.cn). $\mathrm{HCl}(36 \%), \mathrm{H}_{2} \mathrm{O}_{2}(30 \%), \mathrm{KOH}$, and $\mathrm{KCl}$, were purchased from Xilong Chemical Co., Ltd (Guangzhou, China). $\mathrm{H}_{2} \mathrm{PtCl}_{6}$, D-(+)-glucose, uric acid (UA), ascorbic acid (AA) and 4-acetamidophenol (AP) were purchased from Aladdin. All other chemicals used in this work were of analytical grade and used without further purification.

\subsection{Electrodeposition of Pt on interdigitated electrode as counter electrode}

Firstly, the interdigitated device was cleaned sequentially with acetone, absolute ethanol and deionized water. Then the interdigitated device was put into an oven and dried at $60^{\circ} \mathrm{C}$ for
$0.5 \mathrm{~h}$. The interdigitated device was immersed into $1 \mathrm{mM}$ $\mathrm{H}_{2} \mathrm{PtCl}_{6}$ and $0.1 \mathrm{M} \mathrm{KCl}$ solution. One of the interdigitated electrodes worked as the working electrode. Pt mesh and commercial $\mathrm{Ag} / \mathrm{AgCl}$ electrode were used as the counter electrode and reference electrode, respectively. Pt nanoparticles were electrodeposited on the interdigitated electrode at $-0.4 \mathrm{~V}$ for $15 \mathrm{~min}$.

\subsection{Electrodeposition of NPG on interdigitated electrode as working electrode}

Before electrodeposition of the $\mathrm{Au}-\mathrm{Sn}$ alloy, the back of the interdigitated device was fixed on a copper sheet with insulating glue and one of the electrodes was connected to the copper with a conductive silver paste. Then the $\mathrm{Au}-\mathrm{Sn}$ alloy electrodeposition was conducted in a two-electrode electrochemical cell. The interdigitated electrode connected with copper was used as the cathode and the Pt mesh was used as the anode. The Au-Sn alloy was electrodeposited on another interdigitated electrode from a plating solution (Huizhou Leadao Electronic Materials Co., Ltd., China, webpage: http:/www.leadao.cn). A constant current density of $0.8 \mathrm{~A} \mathrm{dm}^{-2}$ was applied to electrodeposit for $10 \mathrm{~min}$, and stirring at $300 \mathrm{rpm}$ was required during the plating process. After the electrodeposition, the interdigitated device was removed from the solution, rinsed with deionized water and dried in the air. The $\mathrm{Au}-\mathrm{Sn}$ alloy-deposited interdigitated device was separated from the copper and immersed into an alkaline solution containing $4 \mathrm{M} \mathrm{KOH}$ and $1 \mathrm{M} \mathrm{H}_{2} \mathrm{O}_{2}$ for 3 days under spontaneous corrosion conditions. After the dealloying process, the interdigitated device was removed from the solution, rinsed with deionized water and dried in the air. Finally, the NPG-modified interdigitated electrode was obtained.

\subsection{Electrodeposition of $\mathrm{Ag} / \mathrm{AgCl}$ as reference electrode}

As shown in Fig. 1a, there is a disk in the centre of the interdigitated device. A hole was drilled on the disk, connecting the circuits from front and back sides of the device through sputtering gold so that the disk can be conducted. The interdigitated device modified with Pt and NPG was immersed into the plating

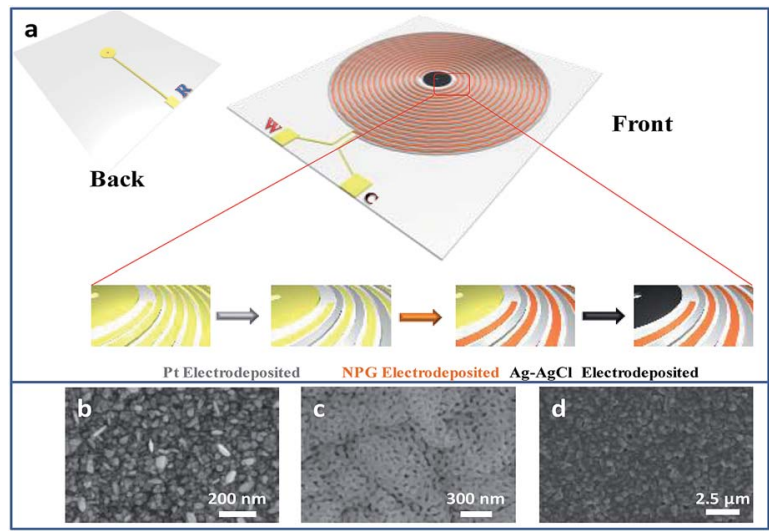

Fig. 1 (a) The scheme and fabrication process of the TEIDGS and the corresponding morphology, (b), (c) and (d), of the three electrodes. 
solution that contained $40 \mathrm{~g} \mathrm{~L}^{-1} \mathrm{AgNO}_{3}, 200 \mathrm{~g} \mathrm{~L}^{-1} \mathrm{Na}_{2} \mathrm{~S}_{2} \mathrm{O}_{3}$ . $5 \mathrm{H}_{2} \mathrm{O}, 40 \mathrm{~g} \mathrm{~L}^{-1} \mathrm{~K}_{2} \mathrm{~S}_{2} \mathrm{O}_{5}, 20 \mathrm{~g} \mathrm{~L}^{-1} \mathrm{NH}_{4} \mathrm{Ac}$ and $0.6 \mathrm{~g} \mathrm{~L}^{-1} \mathrm{CH}_{5} \mathrm{~N}_{3} \mathrm{~S}$. A constant current density of $0.3 \mathrm{~A} \mathrm{dm}^{-2}$ was applied to electrodeposit Ag on the disk for $15 \mathrm{~min}$. The interdigitated device was rinsed with deionized water and then the disk was dipped in an aqueous solution of $0.1 \mathrm{M} \mathrm{KCl}$ and $0.01 \mathrm{M} \mathrm{HCl}$. The potential was swept from -0.15 to $1.05 \mathrm{~V}$ versus a commercial $\mathrm{Ag} / \mathrm{AgCl}$ electrode for five segments at a scan rate of $50 \mathrm{mV} \mathrm{s}{ }^{-1}$ to obtain the final $\mathrm{Ag} / \mathrm{AgCl}$ electrode on the TEIDGS.

\subsection{Material characterization}

The surface morphology and element composition of all the samples were characterized by a scanning electron microscope (SEM; Hitachi S-4800) equipped with energy dispersive X-ray (EDX) element mapping. Transmission electron microscopy (TEM; FEI Tecnai G2 F30) was used to analyse the morphology and structure. X-ray diffraction (XRD) measurements were performed on a Rigaku D/max-2200/PC diffractometer using $\mathrm{Cu} \mathrm{K} \alpha$ radiation to gain the crystal structure of NPG.

\subsection{Electrochemical measurement}

All the electrochemical measurements including cyclic voltammetry (CV), chronoamperometry (CA), and electrochemical impedance spectroscopy (EIS) were performed on Gamry REF 600 Electrochemical Workstation. The single NPG electrode was measured in a conventional three-electrode electrochemical cell, with Pt mesh as the counter electrode and $\mathrm{Ag} / \mathrm{AgCl}$ electrode as the reference electrode. However, the TEIDGS integrated NPG working electrode (WE), Pt counter electrode (CE) and $\mathrm{Ag} / \mathrm{AgCl}$ reference electrode (RE) can be measured in alkaline solution directly. In a solution of $0.1 \mathrm{M} \mathrm{KOH}$ and $0.01 \mathrm{M} \mathrm{KCl}$ containing $5 \mathrm{mM}$ glucose, the EIS test has a frequency range of $0.01 \mathrm{~Hz}$ to $100 \mathrm{kHz}$ and a potential amplitude of $10 \mathrm{mV}$ at a DC bias of $0.1 \mathrm{~V}$.

\section{Result and discussion}

\subsection{Characteristics of the TEIDGS}

Fig. $\mathrm{S} 1 \uparrow$ presents the fabrication process of the interdigitated electrode on ceramic circuit board, which can be further processed into sensors. First, a thin film of Ti-W was magnetronsputtered on an activated alumina ceramic plate. Second, a layer of copper was plated on the Ti-W thin film. Third, the patterns of the interdigitated electrodes were transferred to the ceramic plate by sequentially masking, exposing, etching, and stripping the film. In order to protect the copper wire from oxidative corrosion, a layer of nickel was electrolessly deposited on the Ti-W-Cu interdigitated patterns. Finally, a thin film layer of gold of about $1 \mu \mathrm{m}$ was electro-deposited on the nickel layer to shield the response signals of nickel and copper and improve the conductivity and electrochemical stability of the device. It can be found that the width of each stripe and the interspace between two adjacent stripes of the interdigitated electrode are both around $100 \mu \mathrm{m}$ (Fig. S3a $\dagger$ ), indicating its high quality. The scheme of the TEIDGS and the corresponding fabrication process are demonstrated in Fig. 1a. The working electrode, counter electrode and reference electrode on the precise ceramic circuit board were designed on the front and back sides, separately. It should be noted that in the middle of the helix working and counter electrodes, the reference electrode is composed of two discs (on the front and back sides of the ceramic circuit board) with a small hollow in its center connecting with each other. The whole fabrication process can be divided into three steps. First, a thin layer of Pt particles was electrodeposited on one of the helix pairs as the counter electrode. Second, the Au-Sn alloy was electrodeposited on another helix pair and then the $\mathrm{Sn}$ was dealloyed by soaking in a mixed solution of $\mathrm{KOH}$ and $\mathrm{H}_{2} \mathrm{O}_{2}$ for an adequate period. Finally, $\mathrm{Ag}$ particles were electrodeposited on the reference electrode and then subjected to a CV scan method in a solution containing enough $\mathrm{Cl}^{-}$to form a thin layer of $\mathrm{AgCl}$ on its surface, resulting in the final $\mathrm{Ag} / \mathrm{AgCl}$ reference electrode. The corresponding optical pictures of the different fabrication steps are shown in Fig. S2. $\dagger$ From the SEM images in Fig. 1b-d, it is obvious that NPG owns large quantities of nanopores with an average diameter of 20-50 nm (Fig. 1c). The SEM images of NPG fabricated at different current densities $\left(0.5,0.8,1.1\right.$ and $\left.1.4 \mathrm{~A} \mathrm{dm}^{-2}\right)$ are shown in Fig. S4. $\dagger$ The nano-scale pore size of NPG remained relatively consistent, but the aggregation of large particles was greatly affected by current density. With the increase in current density, more and more large particles were formed on the surface of the electrode, and the flatness was decreased. The aggregation of large particles could result in easier fall off from the substrate and reduce the service life of the electrode. Therefore, the current density in the range of 0.5 to $0.8 \mathrm{~A} \mathrm{dm}^{-2}$ was determined as the optimum preparation condition. The Pt nanoparticles on the counter electrode show a rather homogeneous size of 50-100 nm (Fig. 1b) and the Ag/ $\mathrm{AgCl}$ reference electrode is composed of uniform bulk particles with the size of several microns (Fig. 1d). From the transmission electron microscope (TEM) images in Fig. S5a and b, $\uparrow$ it is clear that the nanopores of NPG are evenly distributed and the pore sizes are all between $20-50 \mathrm{~nm}$. It can be found that NPG possesses abundant angularity, as shown in Fig. S5c. $\uparrow$ The great catalytic activity of NPG is possibly related to the angular structure at these active positions. The selected area electron diffraction (SAED) pattern of NPG indexed as (111), (200), (220) and (311) planes is shown in Fig. S5d, $\uparrow$ suggesting that NPG is polycrystalline. Fig. $56 \dagger$ presents the pore size distributions of NPG. It can be found that nanopores with pore sizes of less than $10 \mathrm{~nm}$ occupy nearly $60 \%$ of the total specific surface area, while the percentage of specific surface area with pore sizes between 25-40 nm reaches almost $40 \%$. These results are well in accordance with the statistical data originated from SEM and TEM images. The XRD test was further performed to obtain the crystal structure of NPG (Fig. 2a). The result demonstrates that the peaks located at $2 \theta=38.2^{\circ}, 44.3^{\circ}, 64.5^{\circ}, 77.5^{\circ}$ and $81.7^{\circ}$ belong to (111), (200), (220), (311) and (222) crystal planes, respectively, indicating that the synthesized NPG matches well with cubic Au (JCPDS\# 04-0784). From the EDS analysis, Au, Cu and Ni were found in the NPG interdigitated electrode, where the $\mathrm{Cu}$ and $\mathrm{Ni}$ elements belong to the transition layer of the interdigitated planar Au substrate (Fig. 2b). There was no signal 

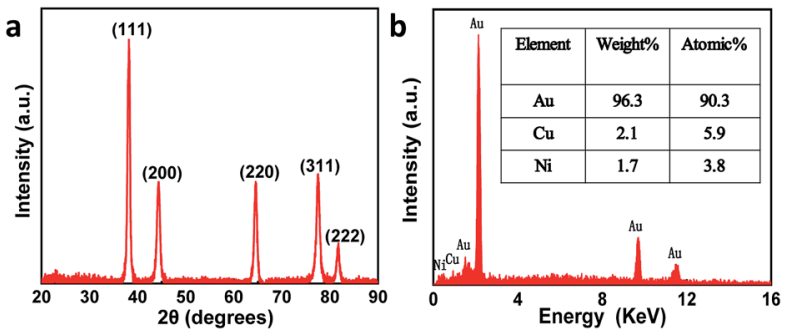

Fig. 2 (a) XRD pattern and (b) EDS of the NPG.

of the Sn element, demonstrating that it was completely removed from the original Au-Sn alloy.

\subsection{The electrochemical performance of NPG}

To evaluate the catalytic performance of NPG for glucose, cyclic voltammetry $(\mathrm{CV})$ tests were performed. Fig. 3a presents the $\mathrm{CV}$ curves of NPG and the original Au substrate before and after adding $5 \mathrm{mM}$ glucose. It was observed that the $\mathrm{Au}$ substrate possessed some catalytic performance since there was an obvious enhancement in current density under the potential of $0.1 \mathrm{~V}$ after $5 \mathrm{mM}$ glucose was added, which was due to its mountainous morphology (as shown in Fig. S3b $\dagger$ ) with hundreds of nanometres, bringing some active sites for the oxidation of the glucose. Compared with the Au substrate, NPG produced more than two times enhancement in the current density under the potential of $0.1 \mathrm{~V}$, indicating its much better ability in sensing glucose. Four peaks appeared in the CV curve of NPG under $0.1 \mathrm{M} \mathrm{KOH}$. The current density started to increase at the potential of around $-0.6 \mathrm{~V}$ and the first two
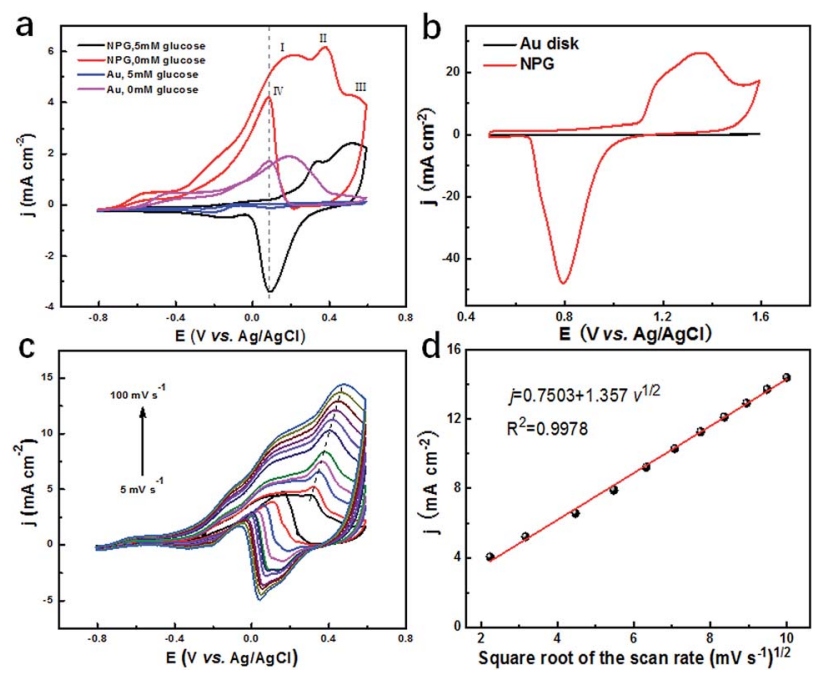

Fig. 3 (a) CV curves of NPG electrode and gold electrode in $0.1 \mathrm{M}$ $\mathrm{KOH}$ and $0.01 \mathrm{M} \mathrm{KCl}$ solution with and without $5 \mathrm{mM}$ glucose at a scan rate of $20 \mathrm{mV} \mathrm{s}^{-1}$; (b) CV curves of NPG electrode and planar Au disk electrode in $0.5 \mathrm{M} \mathrm{H}_{2} \mathrm{SO}_{4}$ at a scan rate of $100 \mathrm{mV} \mathrm{s}^{-1}$; (c) CV curves of NPG electrode with various scan rates $(5,10,20,30,40,50,60,70,80$, $90,100 \mathrm{mV} \mathrm{s}^{-1}$ ) in $0.1 \mathrm{M} \mathrm{KOH}$ and $0.01 \mathrm{M} \mathrm{KCl}$ solution containing $5 \mathrm{mM}$ glucose; (d) a linear calibration curve represents the relationship between the peak current and square root of the scan rate. peaks appeared at around $0.17 \mathrm{~V}$ and $0.33 \mathrm{~V}$. As the potential continued to elevate, more glucose was oxidized and thus the current density increased. After the potential exceeded the third peak at around $0.52 \mathrm{~V}, \mathrm{Au}_{2} \mathrm{O}_{3}$ was produced and occupied the active sites of the $\mathrm{Au}(\mathrm{OH})_{\text {ads }}$, leading to the decline in the current density. When the potential was at a negative going scan, $\mathrm{Au}_{2} \mathrm{O}_{3}$ gradually reduced so that the active sites of $\mathrm{Au}(\mathrm{OH})_{\text {ads }}$ started to increase, resulting in the enhancement of the current density again and the appearance of the fourth peak. CV measurements for NPG in different $\mathrm{pH}$ environments were also carried out (Fig. S7†). It was found that the catalytic performances were poor in acidic $(\mathrm{pH}=1.00$ and 4.00$)$, neutral $(\mathrm{pH}=7.00)$ and weak alkaline $(\mathrm{pH}=9.18)$ conditions. The oxidation of glucose is mainly caused by the hydroxyl radicals (derived from the abundant $\mathrm{OH}^{-}$in the solution) absorbed on the surface of NPG, ${ }^{\mathbf{4 4 , 4 5}}$ which can be described by the following equations (a detailed scheme can be found in Fig. $\mathrm{S} 8 \dagger$ ):

$$
\begin{gathered}
\mathrm{Au}+\mathrm{OH}^{-} \rightarrow \mathrm{Au}(\mathrm{OH})_{\mathrm{ads}}+\mathrm{e}^{-} \\
2 \mathrm{Au}(\mathrm{OH})_{\mathrm{ad}}+\mathrm{C}_{6} \mathrm{H}_{12} \mathrm{O}_{6} \rightarrow 2 \mathrm{Au}+\mathrm{C}_{6} \mathrm{H}_{10} \mathrm{O}_{6}+2 \mathrm{H}_{2} \mathrm{O}
\end{gathered}
$$

Besides, the dissolved oxygen in the electrolyte can be reduced at the Pt counter electrode, as shown in the following equation:

$$
\mathrm{O}_{2}+2 \mathrm{H}_{2} \mathrm{O}+4 \mathrm{e}^{-} \rightarrow 4 \mathrm{OH}^{-}
$$

The overall reaction for the electrocatalytic oxidation of glucose can be expressed by the following equation:

$$
\mathrm{C}_{6} \mathrm{H}_{12} \mathrm{O}_{6}+1 / 2 \mathrm{O}_{2} \rightarrow \mathrm{C}_{6} \mathrm{H}_{10} \mathrm{O}_{6}+\mathrm{H}_{2} \mathrm{O}
$$

The electrochemical surface areas (ECSA) of NPG and the planar gold disk were then calculated through the $\mathrm{CV}$ curves collected in a $0.5 \mathrm{M} \mathrm{H}_{2} \mathrm{SO}_{4}$ solution at a scan rate of $100 \mathrm{mV} \mathrm{s}^{-1}$, as shown in Fig. 3b. The ECSA is determined by the integral area of the gold oxide reduction peak, which is proportional to the reactive surface area of the gold surface. ${ }^{46}$ The much higher ECSA $\left(107.69 \mathrm{~cm}^{2}\right)$ and much larger roughness (215.38) of NPG compared to the planar Au disk $\left(0.12 \mathrm{~cm}^{2}, 0.24\right)$ further verify the superior catalytic performance of the NPG electrode. To clarify which process is in control of the catalytic reaction, CV curves at different scan rates $\left(5-100 \mathrm{mV} \mathrm{s}^{-1}\right)$ were collected in a solution containing $0.1 \mathrm{M} \mathrm{KOH}, 0.01 \mathrm{M} \mathrm{KCl}$ and $5 \mathrm{mM}$ glucose, as shown in Fig. 3c. It can be observed that both peak current and potential increase with the increase in scan rate. As presented in Fig. $3 d$, the current density $j$ demonstrates a liner relationship with the square root of the scan rate with the correlation coefficient $R^{2}=0.9978$, indicating the diffusion controlled electrochemical behaviour. ${ }^{47}$ Above results indicate that NPG can be a great choice to detect glucose. Therefore, it is feasible to fabricate three-electrode integrated devices based on the as synthesized NPG and the electrochemical performance of TEIDGS will be further studied. 


\subsection{The electrochemical performance of the TEIDGS}

To testify the successful design of our TEIDGS, a series of chronoamperometry measurements were performed to investigate its catalytic performances for glucose. First, the typical $j-t$ curves of the TEIDGS, pure Au electrode and the NPG electrode were collected before and after adding $0.1 \mathrm{mM}$ glucose under an applied voltage of $0.1 \mathrm{~V}$, as shown in Fig. $4 \mathrm{a}$. The TEIDGS based on NPG can produce a current density change of $0.30034 \mathrm{~mA}$ $\mathrm{cm}^{-2}$, while the one based on pure Au can only bring a current density change of $0.00355 \mathrm{~mA} \mathrm{~cm} \mathrm{~cm}^{-2}$, presenting around 100 times enhancement in performance. The NPG electrode incorporated with an extra Pt counter electrode and $\mathrm{Ag} / \mathrm{AgCl}$ reference electrode can only produce a current density change of $0.13187 \mathrm{~mA} \mathrm{~cm}^{-2}$, which is nearly half of the performance obtained from the TEIDGS. The above results demonstrate that our TEIDGS based on NPG can overcome drawbacks of both the traditional three-electrode configuration and the poor catalytic ability of the planar Au substrate. The selectivity of the TEIDGS was further confirmed by observing the response situation after some common distractors were added, as shown in Fig. $4 \mathrm{~b}$. Three interferences including AP, AA and UA were added into the $0.1 \mathrm{M} \mathrm{KOH}$ and $0.01 \mathrm{M} \mathrm{KCl}$ solution between two separate drops of $0.1 \mathrm{mM}$ glucose. No obvious response current was observed on the addition of these distractors, which confirmed that our TEIDGSs possess perfect selectivity for glucose. The stable step curve with dramatically increased current density following the gradual increase in the concentration of glucose can be found in Fig. 4c. The minimum detection limit reaches as low as $390 \mathrm{nM}(\mathrm{S} / \mathrm{N}=3$, according to the calculation method
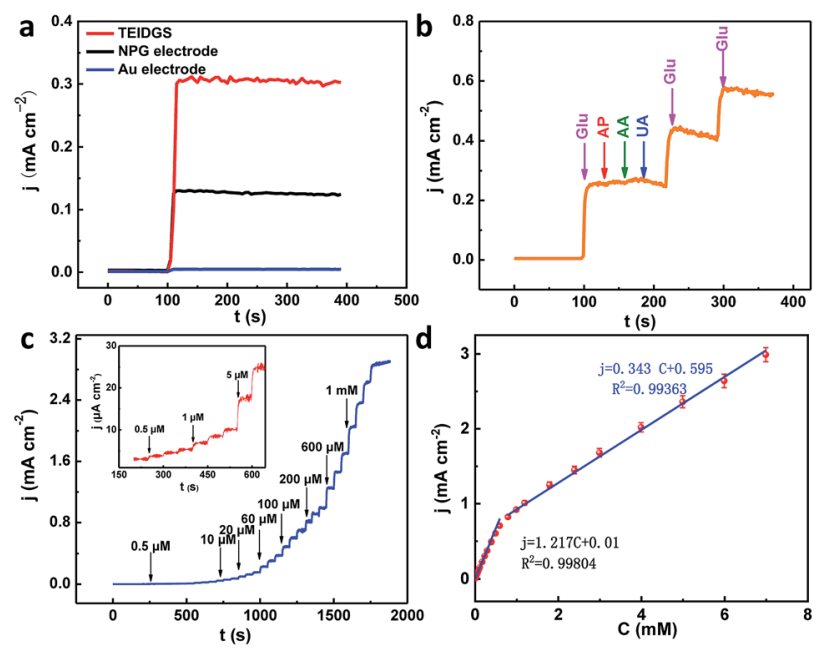

Fig. 4 (a) $j-t$ curves of TEIDGS, NPG electrode and planar Au electrode in $0.1 \mathrm{M} \mathrm{KOH}$ and $0.01 \mathrm{M} \mathrm{KCl}$ solution with $0.1 \mathrm{mM}$ glucose at a constant potential of $0.1 \mathrm{~V}$. (b) The selectivity towards glucose $(0.1$ $\mathrm{mM})$ in the presence of $\mathrm{AP}(10 \mu \mathrm{M}), \mathrm{AA}(10 \mu \mathrm{M})$ and $\mathrm{UA}(10 \mu \mathrm{M})$ at a constant potential of $0.1 \mathrm{~V}$. (c) Chronoamperometric responses of the three-electrode interdigitated device on the successive addition of glucose in $0.1 \mathrm{M} \mathrm{KOH}$ and $0.01 \mathrm{M} \mathrm{KCl}$ solution with a constant potential of $0.1 \mathrm{~V}$ (inset: the magnified curve for $0.5-6 \mu \mathrm{M}$ glucose) (d) the calibration curves (current density versus glucose concentration) of the TEIDGS. of IUPAC), which is much lower than most of the gold-based glucose sensors reported previously (Table 1): $50 \mu \mathrm{M}$ for gold nanowire array, ${ }^{48} 10 \mu \mathrm{M}$ for urchin-like gold submicrostructures, ${ }^{49} 8.7 \mu \mathrm{M}$ for nanoporous gold film, ${ }^{50}$ and comparable to some researches: $500 \mathrm{nM}$ for nanoporous gold ${ }^{22}$ and $200 \mathrm{nM}$ for 3D hierarchical porous $\mathrm{Au}$ networks. ${ }^{23}$ Fig. $4 \mathrm{~d}$ presents the linear relationship between current density and the corresponding glucose concentration. Five parallel samples were tested at the same operational conditions. There are two segments of linear relationship between current density $j$ and the concentration of glucose $C: j=1.217 C+0.010$ in the range of 0.001 to $0.590 \mathrm{mM}$ and $j=0.343 C+0.595$ in the range of 0.590 to $7.00 \mathrm{mM}$ with correlation coefficients of 0.99804 and 0.99363 , respectively. Thus, the corresponding sensitivities can be as high as $1217 \mu \mathrm{A} \mathrm{mM}{ }^{-1} \mathrm{~cm}^{-2}$ and $343 \mu \mathrm{A} \mathrm{mM}{ }^{-1} \mathrm{~cm}^{-2}$ in the ranges of $0.001-0.590 \mathrm{mM}$ and $0.59-7.00 \mathrm{mM}$, respectively, demonstrating much superior performance than most gold nanomaterials ${ }^{22,23,49-53}$ and comparable to gold nanowire arrays $^{48}$ (309 $\left.\mu \mathrm{A} \mathrm{mM}{ }^{-1} \mathrm{~cm}^{-2}\right)$ and gold thin films ${ }^{47}(749 \mu \mathrm{A}$ $\mathrm{mM}^{-1} \mathrm{~cm}^{-2}$ ). It should be noted that the highest detective limit can reach $7.00 \mathrm{mM}$, which is enough for practical glucose sensors since the samples to be tested usually need to be diluted firstly. The long-term stability of the TEIDGS was measured through two strategies, as presented in Fig. 5. First, it can retain a stable current response under $0.1 \mathrm{mM}$ glucose solution for over $5000 \mathrm{~s}$ with only $8.7 \%$ decay (Fig. 5a). Also, the same samples can be kept for nearly three weeks under the same concentration of glucose solution with stable detective performance, as demonstrated in Fig. 5b. Thus, our TEIDGS owns potential in practical applications with stable performance.

Finally, in order to explore the electron transfer and polarized properties of the TEIDGS, EIS measurements were performed. The EIS of the TEIDGS is composed of two semicircuits, which represent charge transfer (high frequency region) and the polarized processes, separately. For comparison, the EIS test was also performed on the NPG electrode with outer counter (standard Pt sheet) and reference electrodes (standard $\mathrm{Ag} / \mathrm{AgCl}$ electrode). As presented in Fig. 6a, both the TEIDGS and NPG electrode own two semi-circuits, which shows the similarity in their transfer character. An equivalent circuit was proposed for representing the EIS results (Fig. 6b), and the fitted values of each element are listed in Table S1. $\dagger$ The TEIDGS possesses a charge transfer resistance $\left(R_{\mathrm{ct}}\right)$ of $1.516 \Omega$, representing the fast charge transfer speed of the TEIDGS. Also, the equivalent series resistance $\left(R_{\mathrm{S}}\right)$ of the TEIDGS $(2.362 \Omega)$ is much smaller than that of the NPG electrode (16.930 $\Omega$ ), indicating that by using this novel three-electrode structure, the $R_{\mathrm{S}}$ including the ohmic resistance from the electrolyte, the surface and body resistance of the electrode for the TEIDGS can be obviously decreased. Considering the polarized process, a constant phase element (CPE or Q) is adopted. CPE is defined by two parameters, CPE-T and CPE-P. Usually, when CPE-P is 0.5 , this element is controlled by the diffusion process (Warburg impedance). If CPE-P is 1 or 0 , it represents an ideal capacitor or pure resistor, respectively. ${ }^{\mathbf{5 4 , 5 5}}$ In these two structures, the values of CPE-P for the TEIDGS and NPG electrode are fitted as 0.9018 and 0.5493 . Thus, the polarized process of the NPG electrode is 
Table 1 Performance comparison of this work and previous researches based on Au nanomaterials

\begin{tabular}{|c|c|c|c|c|}
\hline Glucose sensor & $\begin{array}{l}\text { Applied potential } \\
\text { (V) }\end{array}$ & Sensitivity $\left(\mu \mathrm{A} \mathrm{mM}{ }^{-1} \mathrm{~cm}^{-2}\right)$ & $\operatorname{LOD}(\mu \mathrm{M})$ & Ref. \\
\hline Nanoporous gold & 0.15 & $24.1,96.7$ & 0.5 & 22 \\
\hline Gold thin film & 0.1 & 749.2 & 9.0 & 47 \\
\hline Gold nanowire array & -0.4 & 309.0 & 50.0 & 48 \\
\hline Urchin-like gold submicrostructures & 0.32 & 16.8 & 10.0 & 49 \\
\hline Porous gold cluster film & 0.1 & 10.8 & 1.0 & 52 \\
\hline Dendrite-like gold nanostructures & 0.15 & 190.7 & 50.0 & 53 \\
\hline Three-electrode interdigitated device & 0.1 & $1217.0,343.0$ & 0.39 & This work \\
\hline
\end{tabular}
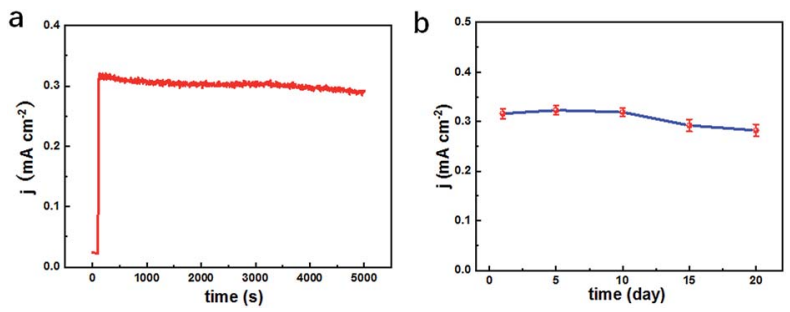

Fig. 5 Long-term stability tests of the TEIDGS in $0.1 \mathrm{M} \mathrm{KOH}$ and $0.01 \mathrm{M} \mathrm{KCl}$ solution containing $0.1 \mathrm{mM}$ glucose for (a) over $5000 \mathrm{~s}$ and (b) 20 days.

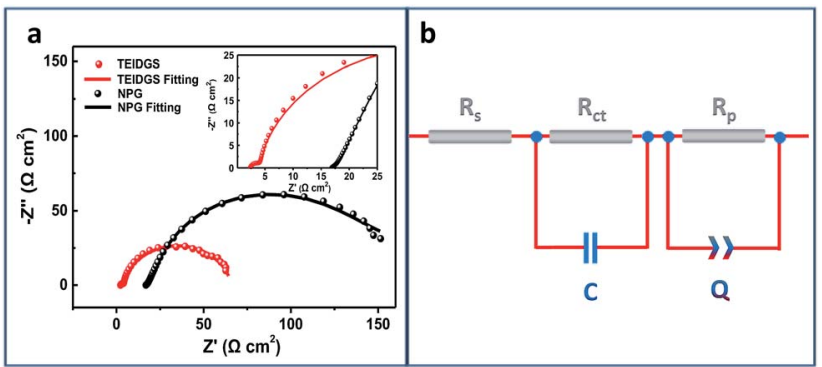

Fig. 6 (a) Electrochemical impedance spectra (EIS) of the TEIDGS and the single NPG electrode integrated with outer counter and reference electrodes in $0.1 \mathrm{M} \mathrm{KOH}$ and $0.01 \mathrm{M} \mathrm{KCl}$ solution containing $5 \mathrm{mM}$ glucose and (b) the corresponding equivalent circle.

closer to the Warburg diffusion, and the TEIDGS is more associated with the capacitive behaviour. Thus, the response process for the oxidation of glucose on the TEIDGS can be more sensitive than on the NPG electrode with outer counter and reference electrodes. It can be also found that the TEIDGS owns a polarized resistance $\left(R_{\mathrm{p}}\right)$ of $62.0 \Omega$, which is smaller than the $R_{\mathrm{p}}$ for the NPG electrode (100.6 $\Omega$ ). The lower $R_{\mathrm{p}}$ of the TEIDGS can ascribe to the fact that the space between the working electrode and the counter electrode is sufficiently small (100 $\mu \mathrm{m})$ and overlaps the diffusion layer $(0.1-0.001 \mathrm{~mm})$ of the bulk solution region between two electrodes. Therefore, the resistance of the glucose molecule diffusion process (bulk solution $\rightarrow$ diffusion layer $\rightarrow$ electrode surface) is reduced, thereby enhancing the response current. In addition, by comparing the EIS data of the TEIDGS, NPG and originally planar Au electrodes (Fig. S9†), it's obvious that the planar Au electrode almost has a diffusion controlled process, which can hinder the redox process greatly and result in the poor catalytic performance for glucose. All of the above confirm that the smart three-electrode design and small space between the working and counter electrodes of the TEIDGS can effectively alleviate the concentration polarization and can be helpful for better charge transfer and a polarized process.

\section{Conclusions}

Herein, a non-enzymatic three-electrode interdigitated device based on the NPG electrode was successfully designed and fabricated as a high-performance glucose sensor. Three electrodes including NPG as the working electrode, Pt particles as the counter electrode and $\mathrm{Ag} / \mathrm{AgCl}$ as the reference electrode were integrated into one single ceramic plate circuit. The innovative design of the three-electrode structure and the small space between the working electrode and counter electrode can effectively decrease the concentration polarization of the whole device, thus resulting in smaller electrochemical resistances $\left(R_{\mathrm{s}}\right.$, $R_{\text {ct }}$ and $R_{\mathrm{p}}$ ) and an excellent catalytic ability for glucose. It can achieve a high detective sensitivity for glucose of $1217 \mu \mathrm{AmM}^{-1}$ $\mathrm{cm}^{-2}$ and $343 \mu \mathrm{AmM}^{-1} \mathrm{~cm}^{-2}$ in the ranges of $0.001-0.590 \mathrm{mM}$ and 0.59-7.00 mM, respectively, and a rather low detective limit of $390 \mathrm{nM}$. In addition, this TEIDGS possesses strong resistance against other interferences, indicating the excellent selectivity. More excitingly, it can be stably operated for nearly three weeks, presenting the potential as a recyclable and long-term glucose sensor. The reasonable design of the three electrodes in a single plane device is easy to be transferred to other substrates such as flexible ones. The novel TEIDGS based on NPG can provide a promising structure design and meaningful material strategy for the future development of glucose sensors.

\section{Conflicts of interest}

There are no conflicts to declare. 


\section{Acknowledgements}

Dr G. Cui and J. Zhao gratefully acknowledge the financial support by the National Natural Science Foundation of China (51271205, 50801070, 51571093), "Project of Science and Technology Plan" by Chinese central authority university fund (2015ZM094, 16lgjc6). This work was also supported by NSFC, China (21622509, 21475122, 21527806), Department of Science and Techniques of Jilin Province (20160201008GX), Jilin Province Development and Reform Commission (2016C014 and 2017C053-1), and Science and Technology Bureau of Changchun (15SS05). We thank Prof. Yexiang Tong and Prof. Guangqin Li from Sun Yat-sen University for their helpful suggestions to this work.

\section{References}

1 IDF, IDF Diabetes Atlas, 2017, https:/www.idf.org/aboutdiabetes/what-is-diabetes.html.

2 A. Heller and B. Feldman, Chem. Rev., 2008, 108, 2482-2505. 3 M. M. Rahman, A. J. Ahammad, J. H. Jin, S. J. Ahn and J. J. Lee, Sensors, 2010, 10, 4855-4886.

4 S. Y. Tee, C. P. Teng and E. Ye, Mater. Sci. Eng., C, 2017, 70, 1018-1030.

5 A. Salek-Maghsoudi, F. Vakhshiteh, R. Torabi, S. Hassani, M. R. Ganjali, P. Norouzi, M. Hosseini and M. Abdollahi, Biosens. Bioelectron., 2018, 99, 122-135.

6 S. Park, H. Boo and T. D. Chung, Anal. Chim. Acta, 2006, 556, 46-57.

7 N. Muthuchamy, A. Gopalan and K. P. Lee, $R S C A d v$., 2018, 8, 2138-2147.

8 C. Y. Chen, M. Shi, M. W. Xue and Y. J. Hu, $R S C A d v .$, 2017, 7, 22208-22214.

9 Y. Zhang, Y. Zhang, H. Zhu, S. D. Li, C. Jiang, R. J. Blue and Y. Su, J. Alloys Compd., 2019, 780, 98-106.

10 L. Y. Chen, T. Fujita, Y. Ding and M. W. Chen, Adv. Funct. Mater., 2010, 20, 2279-2285.

11 X. Y. Lang, H. Y. Fu, C. Hou, G. F. Han, P. Yang, Y. B. Liu and Q. Jiang, Nat. Commun., 2013, 4, 2169.

12 K. Tian, M. Prestgard and A. Tiwari, Mater. Sci. Eng., C, 2014, 41, 100-118.

13 X. Luo, M. Huang, L. Bie, D. He, Y. Zhang and P. Jiang, RSC Adv., 2017, 7, 23093-23101.

14 T. N. N. Dau, V. H. Vu, T. T. Cao, V. C. Nguyen, C. T. Ly, D. L. Tran, T. T. N. Pham, N. T. Loc, B. Piro and T. T. Vu, Sens. Actuators, B, 2019, 283, 52-60.

15 P. Chakraborty, S. Dhar, K. Debnath, T. Majumder and S. P. Mondal, Sens. Actuators, B, 2019, 283, 776-785.

16 H.-H. Li, S. Zhao, M. Gong, C.-H. Cui, D. He, H.-W. Liang, L. Wu and S.-H. Yu, Angew. Chem., 2013, 125, 7620-7624.

17 E. Ye, M. D. Regulacio, S. Y. Zhang, X. J. Loh and M. Y. Han, Chem. Soc. Rev., 2015, 44, 6001-6017.

18 S. Nantaphol, T. Watanabe, N. Nomura, W. Siangproh, O. Chailapakul and Y. Einaga, Biosens. Bioelectron., 2017, 98, 76-82.

19 R. Ojani, E. Hasheminejad and J. B. Raoof, Int. J. Hydrogen Energy, 2014, 39, 8194-8203.
20 J. Wang, H. Gao, F. Sun and C. Xu, Sens. Actuators, B, 2014, 191, 612-618.

21 A. Zhao, Z. Zhang, P. Zhang, S. Xiao, L. Wang, Y. Dong, H. Yuan, P. Li, Y. Sun, X. Jiang and F. Xiao, Anal. Chim. Acta, 2016, 938, 63-71.

22 G.-X. Zhong, W.-X. Zhang, Y.-M. Sun, Y.-Q. Wei, Y. Lei, H.-P. Peng, A.-L. Liu, Y.-Z. Chen and X.-H. Lin, Sens. Actuators, B, 2015, 212, 72-77.

23 S. L. Zhong, J. Zhuang, D. P. Yang and D. Tang, Biosens. Bioelectron., 2017, 96, 26-32.

24 X. Xiao, P. Si and E. Magner, Bioelectrochemistry, 2016, 109, 117-126.

25 J. Erlebacher, M. J. Aziz, A. Karma, N. Dimitrov and K. Sieradzki, Nature, 2001, 410, 450-453.

26 Y. J. Pei, M. Hu, F. H. Tu, X. Y. Tang, W. Huang, S. Chen, Z. L. Li and Y. Xia, Biosens. Bioelectron., 2018, 117, 758-765.

27 J. K. Bhattarai, D. Neupane, B. Nepal, V. Mikhaylov, A. V. Demchenko and K. J. Stine, Nanomaterials, 2018, 8(3), 171.

28 J. Zhao, X. Zou, P. Sun and G. Cui, Sci. Rep., 2017, 7, 17857. 29 Z. Li, Y. He, X. Ke, L. Gan, J. Zhao, G. Cui and G. Wu, J. Power Sources, 2015, 294, 136-140.

30 Y. Xu, X. Ke, C. Yu, S. Liu, J. Zhao, G. Cui, D. Higgins, Z. Chen, Q. Li and G. Wu, Nanotechnology, 2014, 25, 445602.

31 X. Ke, Y. Xu, C. Yu, J. Zhao, G. Cui, D. Higgins, Q. Li and G. Wu, J. Power Sources, 2014, 269, 461-465.

32 A. Abellán-Llobregat, I. Jeerapan, A. Bandodkar, L. Vidal, A. Canals, J. Wang and E. Morallón, Biosens. Bioelectron., 2017, 91, 885-891.

33 Y. Chen, S. Lu, S. Zhang, Y. Li, Z. Qu, Y. Chen, B. Lu, X. Wang and X. Feng, Sci. Adv., 2017, 3, e1701629.

$34 \mathrm{~W}$. Hou, Z. Shi, Y. Guo, X. Sun and X. Wang, Bioprocess Biosyst. Eng., 2017, 40, 1419-1425.

35 C. Jungreuthmayer, G. M. Birnbaumer, P. Ertl and J. Zanghellini, Sens. Actuators, B, 2012, 162, 418-424.

36 M. S. Abdul Rahman, S. C. Mukhopadhyay, P.-L. Yu, J. Goicoechea, I. R. Matias, C. P. Gooneratne and J. Kosel, J. Food Eng., 2013, 114, 346-360.

37 H. Lee, C. Song, Y. S. Hong, M. S. Kim, H. R. Cho, T. Kang, K. Shin, S. H. Choi, T. Hyeon and D. H. Kim, Sci. Adv., 2017, 3, e1601314.

38 N. Y. Kim, K. K. Adhikari, R. Dhakal, Z. Chuluunbaatar, C. Wang and E. S. Kim, Sci. Rep., 2015, 5, 7807.

39 J. Gui, Y. Zhu, L. Zhang, X. Shu, W. Liu, S. Guo and X. Zhao, Appl. Phys. Lett., 2018, 112, 072902.

40 N. Liu and Y. Gao, Small, 2017, 13(45), 1701989.

41 D. Pech, M. Brunet, H. Durou, P. Huang, V. Mochalin, Y. Gogotsi, P. L. Taberna and P. Simon, Nat. Nanotechnol., 2010, 5, 651-654.

42 X. Li, L. Luo and R. M. Crooks, Anal. Chem., 2017, 89, 42944300.

43 S. H. Ko, Y. A. Song, S. J. Kim, M. Kim, J. Han and K. H. Kang, Lab Chip, 2012, 12, 4472-4482.

44 X. Fang, L. Wang, P. K. Shen, G. Cui and C. Bianchini, J. Power Sources, 2010, 195, 1375-1378.

45 G. Cui, P. K. Shen, H. Meng, J. Zhao and G. Wu, J. Power Sources, 2011, 196, 6125-6130. 
46 A. Sukeri, L. P. Saravia and M. Bertotti, Phys. Chem. Chem. Phys., 2015, 17, 28510-28514.

47 C.-W. Hsu, F.-C. Su, P.-Y. Peng, H.-T. Young, S. Liao and G.-J. Wang, Sens. Actuators, B, 2016, 230, 559-565.

48 S. Cherevko and C.-H. Chung, Sens. Actuators, B, 2009, 142, 216-223.

49 F. Xu, K. Cui, Y. Sun, C. Guo, Z. Liu, Y. Zhang, Y. Shi and Z. Li, Talanta, 2010, 82, 1845-1852.

50 Y. Xia, W. Huang, J. Zheng, Z. Niu and Z. Li, Biosens. Bioelectron., 2011, 26, 3555-3561.
51 L. Y. Chen, X. Y. Lang, T. Fujita and M. W. Chen, Scr. Mater., 2011, 65, 17-20.

52 L. Han, S. Zhang, L. Han, D.-P. Yang, C. Hou and A. Liu, Electrochim. Acta, 2014, 138, 109-114.

53 H. Shu, L. Cao, G. Chang, H. He, Y. Zhang and Y. He, Electrochim. Acta, 2014, 132, 524-532.

54 M. E. Orazem and B. Tribollet, Electrochemical Impedance Spectroscopy, John Wiley \& Sons, Hoboken, New Jersey, 2008.

55 J. Yang, J. H. Yu, J. Rudi Strickler, W. J. Chang and S. Gunasekaran, Biosens. Bioelectron., 2013, 47, 530-538. 